\title{
The differential effects of anemia on mortality in young and elderly end-stage renal disease patients
}

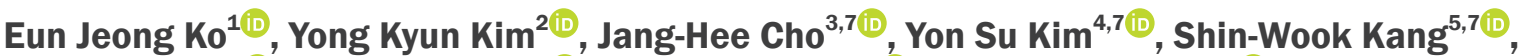 \\ Nam-Ho Kim ${ }^{6,7(\mathbb{D})}$, Yong-Lim Kim ${ }^{3,7(\mathbb{D})}$, Chul Woo Yang ${ }^{1,7(\mathbb{D}}$, Byung Ha Chung ${ }^{1,7(\mathbb{D})}$ \\ 'Department of Internal Medicine, Seoul St. Mary's Hospital, College of Medicine, The Catholic University of Korea, Seoul, Republic of \\ Korea, ${ }^{2}$ Department of Internal Medicine-Nephrology, St. Vincent's Hospital, College of Medicine, The Catholic University of Korea, \\ Suwon, Republic of Korea, ${ }^{3}$ Department of Internal Medicine, Kyungpook National University Hospital, School of Medicine, Kyungpook \\ National University, Daegu, Republic of Korea, ${ }^{4}$ Department of Internal Medicine, Seoul National University College of Medicine, Seoul, \\ Republic of Korea, ${ }^{5}$ Department of Internal Medicine, Yonsei University College of Medicine, Seoul, Republic of Korea, ${ }^{6}$ Department of \\ Internal Medicine, Chonnam National University Medical School, Gwangju, Republic of Korea, ${ }^{7}$ Clinical Research Center for End-Stage \\ Renal Disease, Daegu, Republic of Korea
}

Background: The aim of this study was to compare the effect of anemia on clinical outcomes according to age in patients with end-stage renal disease (ESRD).

Methods: A total of 3,409 patients from the Clinical Research Center for ESRD were included and divided into three groups by age: age $<40(n=488), 40 \leq$ age $<60(n=1,650)$, and age $\geq 60(n=1,271)$. We compared overall and cardiovascular mortality, and all-cause and cardiovascular hospitalization according to mean hemoglobin $(\mathrm{Hb})$ concentration.

Results: Among participants $\geq 60$ years of age, the $\mathrm{Hb}<10 \mathrm{~g} / \mathrm{dL}$ group had greater all-cause mortality (adjusted hazard ratio [HR], 2.098; 95\% confidence interval [Cl], 1.567-2.808; $P<0.001$ ) than the $10 \leq \mathrm{Hb}<12 \mathrm{~g} / \mathrm{dL}$ group, whereas among participants $<40$ years of age, the $\mathrm{Hb} \geq 12 \mathrm{~g} / \mathrm{dL}$ group had greater mortality than the $10 \leq \mathrm{Hb}<12 \mathrm{~g} / \mathrm{dL}$ group. Moreover, in participants $\geq 60$ years of age, the HR for all-cause hospitalization for the $\mathrm{Hb}<10 \mathrm{~g} / \mathrm{dL}$ group was significantly greater than that of the $10 \leq \mathrm{Hb}<12 \mathrm{~g} / \mathrm{dL}$ group (HR, 1.472; 95\% Cl, 1.057-2.051; $P=0.022$ ), whereas it was significantly lower in the $\mathrm{Hb} \geq 12 \mathrm{~g} / \mathrm{dL}$ group (HR, 0.544; 95\% $\mathrm{Cl}, 0.362-0.820 ; P=0.004$ ) However, among participants $<40$ years of age, the incidence of all-cause hospitalization did not differ according to the $\mathrm{Hb}$ concentration (HR, 1.273; 95\% Cl, 0.814-1.991; $P=0.290$ for the $\mathrm{Hb}<10 \mathrm{~g} / \mathrm{dL}$ group; reference, $10 \leq \mathrm{Hb}<12 \mathrm{~g} / \mathrm{dL} ; \mathrm{HR}, 0.787$; 95\% $\mathrm{Cl}, 0.439-1.410 ; P=0.265$ for $\mathrm{Hb} \geq 12 \mathrm{~g} / \mathrm{dL}$ group).

Conclusion: The impact of anemia on mortality was more significant in elderly ESRD patients. Strict monitoring and management of anemia should be required for elderly ESRD patients.

Keywords: Aged, Cardiovascular diseases, Dialysis, Hemoglobin target, Mortality

Received November 28, 2019; Revised March 11, 2020; Accepted March 29, 2020

Edited by Young-Ki Lee, Hallym University, Seoul, Republic of Korea

Correspondence: Byung Ha Chung

Division of Nephrology, Department of Internal Medicine, Seoul St. Mary's Hospital, College of Medicine, The Catholic University of Korea, 222 Banpo-daero, Seocho-gu, Seoul 06591, Republic of Korea. E-mail: chungbh@catholic.ac.kr

Copyright (C) 2020 by The Korean Society of Nephrology

(a) This is an open-access article distributed under the terms of the Creative Commons Attribution Non-Commercial License (http://creativecommons.org/ licenses/by-nc-nd/4.0/), which permits unrestricted non-commercial use, distribution, and reproduction in any medium, provided the original work is properly cited. 


\section{Introduction}

Anemia is an important complication of end-stage renal disease (ESRD), and treatment of anemia is correlated with an improvement in the patient's quality of life, and with a reduction in morbidity and mortality [1-3]. Therefore, it is strongly recommended to use erythropoiesisstimulating agents (ESAs) and iron therapy, which are considered beneficial for the correction of anemia, in patients with ESRD $[4,5]$. However, the results of some studies have suggested potential harm due to overtreatment of anemia when employing ESAs, defined as achieving a hemoglobin $(\mathrm{Hb})$ concentration of $12 \mathrm{~g} / \mathrm{dL}$ and above, which may potentially lead to increased cardiovascular events and mortality $[6,7]$. The Kidney Disease Improving Global Outcomes (KDIGO) guidelines therefore currently recommend maintaining $\mathrm{Hb}$ concentrations between 10 to $12 \mathrm{~g} / \mathrm{dL}$ in clinical practice [4].

Despite these recommendations, a previous report suggested that the optimal $\mathrm{Hb}$ concentration may vary according to the patient's age [7]. This report found that in children on hemodialysis (HD), Hb concentrations of $12 \mathrm{~g} / \mathrm{dL}$ and above are not associated with increased incidences of cardiovascular visits, mortality, or allcause and cardiovascular disease (CVD)-related hospitalizations, in contrast to the reported harmful impact of overcorrected $\mathrm{Hb}$ in adult ESRD patients. Another study reported that anemia resulted in a more significant impact in elderly ESRD patients than in younger patients with respect to CVD and ESRD-related mortality of that population demographic $[6,7]$. These studies suggest that anemia and/or overcorrected $\mathrm{Hb}$ are associated with differential impacts on patient outcomes according to the patient's age.

Based on above findings, the aim of this study was to investigate whether anemia is associated with differential impacts on clinical outcomes according to age group using a well-established nation-wide ESRD cohort within Clinical Research Center for ESRD (CRC-ESRD).

\section{Methods}

\section{Study population}

We analyzed the CRC-ESRD data. The CRC-ESRD database contained a total of 5,244 cases from 31 centers in
Korea. The cohort was established in April 2009, and included adult ( $>18$ years of age) dialysis patients. For the present study, we excluded patients whose age data was not available, or whose $\mathrm{Hb}$ concentrations had not been measured at least three times during the study period; a total of 1,835 patients were excluded, and 3,409 patients were included in the final analyses (Fig. 1).

A total of 2,058 patients on HD, 1,332 patients on peritoneal dialysis (PD), 7 patients with changes in treatment modality (HD $\rightarrow$ PD or PD $\rightarrow$ HD), and 12 patients with missing data regarding treatment modality were enrolled in this cohort. Additionally, 1,157 incident and 2,252 prevalent dialysis patients were included in the analyses.

The CRC registry for ESRD was approved by the medical ethics committees of all participating hospitals, and informed consent was obtained from all patients before inclusion. All participants were assigned to one of three groups (age $<40,40 \leq$ age $<60$, or age $\geq 60$ years) according to their age at enrollment of this study for maintained HD patients, or according to their age at the initiation of dialysis for incidental dialysis patients.

\section{Data collection}

This was a prospective cohort study of dialysis patients in Korea receiving HD for ESRD during the years 2009 to 2015. The baseline demographic and clinical data,

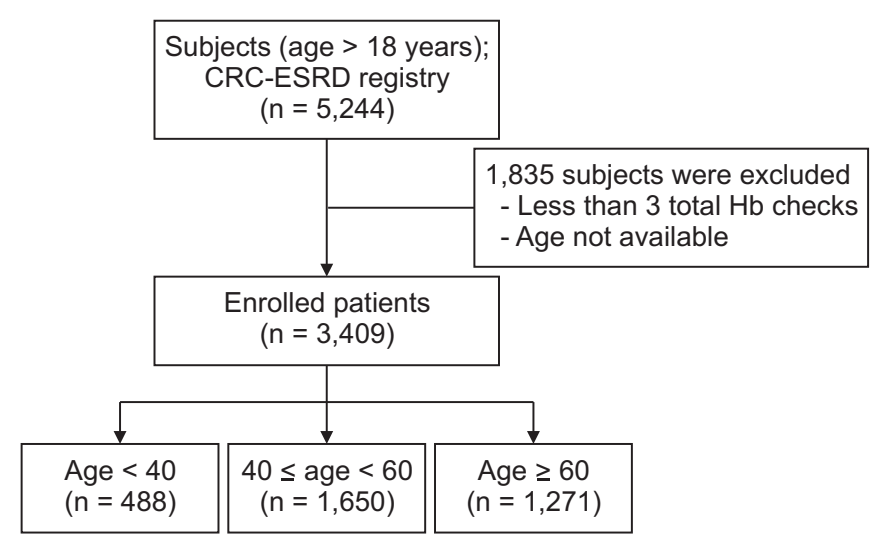

Figure 1. Distribution of patient population according to patient age. Of the 5,244 subjects included in the Clinical Research Center for end-stage renal disease (CRC-ESRD) registry, 1,835 subjects were excluded due to lack of information regarding age or hemoglobin $(\mathrm{Hb})$ concentration. Therefore, 3,409 patients were included: 488 were younger than 40 years of age, 1,650 were between 40 and 60 years of age, and 1,271 were 60 years of age or older. 
including age, sex, and laboratory investigations, were recorded for all patient participants. For the assessment of mean $\mathrm{Hb}$ concentration, we calculated the average of every serum $\mathrm{Hb}$ measurement during the follow-up period. The patients were divided into 3 groups according to their mean $\mathrm{Hb}$ concentration as $\mathrm{Hb}<10 \mathrm{~g} / \mathrm{dL}, 10 \leq$ $\mathrm{Hb}<12 \mathrm{~g} / \mathrm{dL}$, and $\mathrm{Hb} \geq 12 \mathrm{~g} / \mathrm{dL}$ [7]. We also categorized patients according to age as $<40$ years, $40 \leq$ age $<60$ years, and age $\geq 60$ years [8].

Baseline demographic and clinical data including age, gender, height, weight, co-morbidities, laboratory investigations, and therapeutic characteristics were recorded. Additionally, serum $\mathrm{Hb}$, albumin, ferritin, transferrin saturation (TSAT) concentrations were determined from the patients' blood samples. The single-pool Kt/V (spKt/ V) was determined using two-point urea modelling based on the intradialytic reduction in blood urea and intradialytic weight loss. For assessment of co-morbidities, modified Charlson comorbidity scores were used.

\section{Outcomes}

The primary outcome of this study was a review of all- cause mortality. For each death, the principal investigator at the given institution completed a form recording the cause of death according to the CRC registry for ESRD study classification. The median follow-up duration was 24.4 months (3 to 81 months), and the dates and causes of mortality were immediately reported throughout the follow-up period. Additionally, the secondary outcomes of this study were CVD-related mortality, all-cause hospitalization, and CVD-related hospitalization. A report of CVD-related mortality or hospitalization referred to death or admission due to a cardiovascular event, such as heart failure, arrhythmia, ischemic cardiovascular event, or stroke.

\section{Statistical analyses}

The patient characteristics were examined using descriptive statistics for continuous variables (mean, median) and categorical variables (number [\%]), and the results were stratified by patient $\mathrm{Hb}$ concentration at baseline. A $\chi^{2}$ tests for independence was used to test for differences by $\mathrm{Hb}$ group. Similarly, we summarized the outcomes (death, hospitalizations, and cardiac events)

Table 1. Comparison of the baseline characteristics of the study population according to patient age

\begin{tabular}{|c|c|c|c|c|}
\hline Characteristic & Age $<40$ years & $40 \leq$ age $<60$ years & Age $\geq 60$ years & $P$ value \\
\hline No. of patients & $488(14.3)$ & $1,650(48.4)$ & $1,271(37.3)$ & \\
\hline Mean age of patients (yr) & 33.6 & 51.6 & 68.8 & $<0.001$ \\
\hline Male sex & $268(54.9)$ & $915(55.5)$ & $761(59.9)$ & 0.064 \\
\hline Cause of ESRD & & & & $<0.001$ \\
\hline DM & $100(20.5)$ & $687(41.6)$ & $627(49.3)$ & \\
\hline GN & $158(32.4)$ & $251(15.2)$ & $104(8.2)$ & \\
\hline Renal vascular disease & $4(0.8)$ & $0(0)$ & $2(0.2)$ & \\
\hline Other & $226(46.3)$ & $712(43.2)$ & $538(42.3)$ & \\
\hline Duration of dialysis (mo) & 24.6 & 29.3 & 28.0 & 0.106 \\
\hline Incidental dialysis & $195(40.0)$ & $531(32.2)$ & $431(33.9)$ & 0.006 \\
\hline Mean $\mathrm{Hb}$ concentration (g/dL) & & & & $<0.001$ \\
\hline $\mathrm{Hb}<10$ & $148(30.3)$ & $436(26.4)$ & $274(21.6)$ & \\
\hline $10 \leq \mathrm{Hb}<12$ & $274(56.1)$ & $1,068(64.7)$ & $874(68.8)$ & \\
\hline $\mathrm{Hb} \geq 12$ & $66(13.5)$ & $146(8.8)$ & $123(9.7)$ & \\
\hline Mean albumin (g/dL) & 3.5 & 3.4 & 3.5 & 0.337 \\
\hline Mean ferritin $(\mathrm{ng} / \mathrm{mL})$ & 245 & 279 & 308 & 0.126 \\
\hline Mean TSAT (\%) & 33.1 & 32.0 & 32.5 & 0.136 \\
\hline Mean iPTH (pg/mL) & 664.6 & 662.4 & 634.0 & 0.663 \\
\hline Mean CRP (mg/L) & 3.24 & 2.30 & 2.62 & 0.160 \\
\hline
\end{tabular}

Data are presented as number (\%) or number only.

CRP, C-reactive protein; DM, diabetes mellitus; ESRD, end-stage renal disease; Hb, hemoglobin; iPTH, intact parathyroid hormone; GN, glomerulonephritis; TSAT, transferrin saturation. 
with descriptive statistics (number [\%]). Broadly speaking, the confidence intervals (CIs) were estimated using a normal approximation of the Poisson distribution. Last, we estimated the adjusted HR of mortality using a Cox proportional hazards model. In this case, the models were adjusted for all patient demographic and clinical characteristics studied, such as gender, primary renal disease, duration of dialysis, modified Charlson comorbidity index, and mean intact parathyroid hormone level (iPTH). All results were stratified by mean $\mathrm{Hb}$ groups with $\mathrm{Hb}$ concentrations with 10 to $<12 \mathrm{~g} / \mathrm{dL}$ as the reference, $P$ values less than 0.05 were considered statistically significant. All analyses were conducting using IBM SPSS Statistics for Windows ver. 21.0 (IBM Corp., Armonk, NY, USA) and MEDCALC version 15.5 (MedCalc, Mariakerke, Belgium).

A

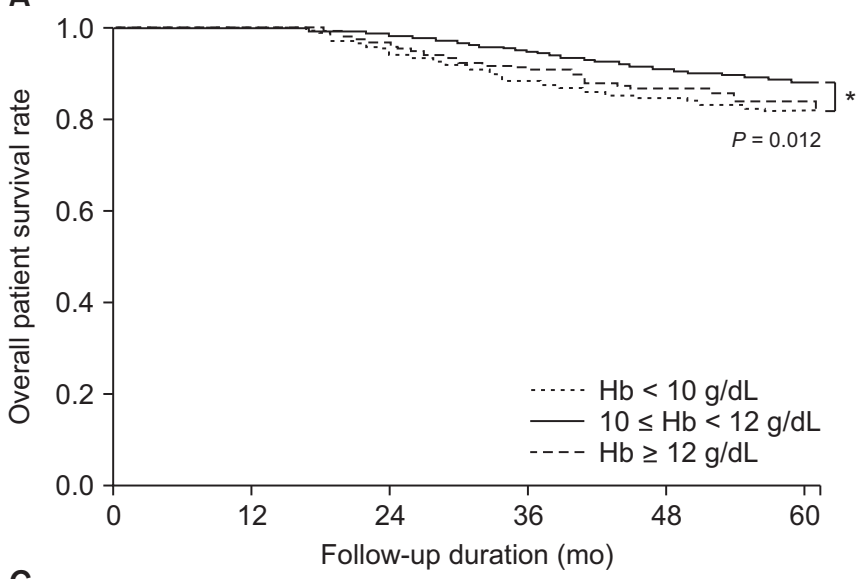

C

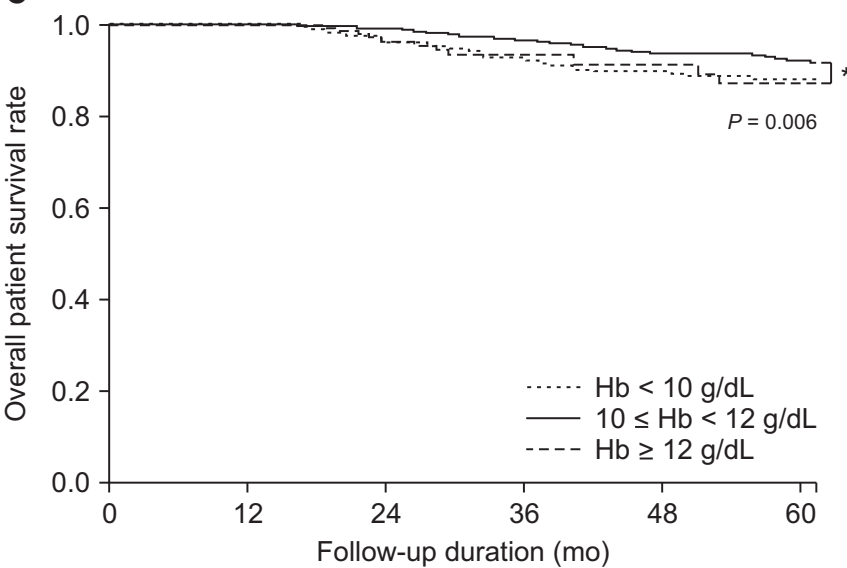

\section{Results}

\section{Baseline characteristics}

Among the study population, $14.3 \%(\mathrm{n}=488)$ were $<40$ years of age, $48.4 \%(n=1,650)$ were $40 \leq$ age $<60$ years of age, and $37.3 \%(n=1,271)$ were $\geq 60$ years of age. Table 1 presents the baseline characteristics among different groups according to the patient's age. Generally, the gender distribution was not different within groups. The cause of ESRD was different according to the patients' ages, and diabetes mellitus (DM) was the most common cause of ESRD in the age $\geq 60$ years group (49.3\%). In contrast, glomerulonephritis was the most common cause of ERSD in both of the younger age groups (age $<40$ years and $40 \leq$ age $<60$ groups; $P<0.001$ for each). There were no differences between the mean durations of dialysis in all the groups $(P=0.106)$, which were 24.6 months

B

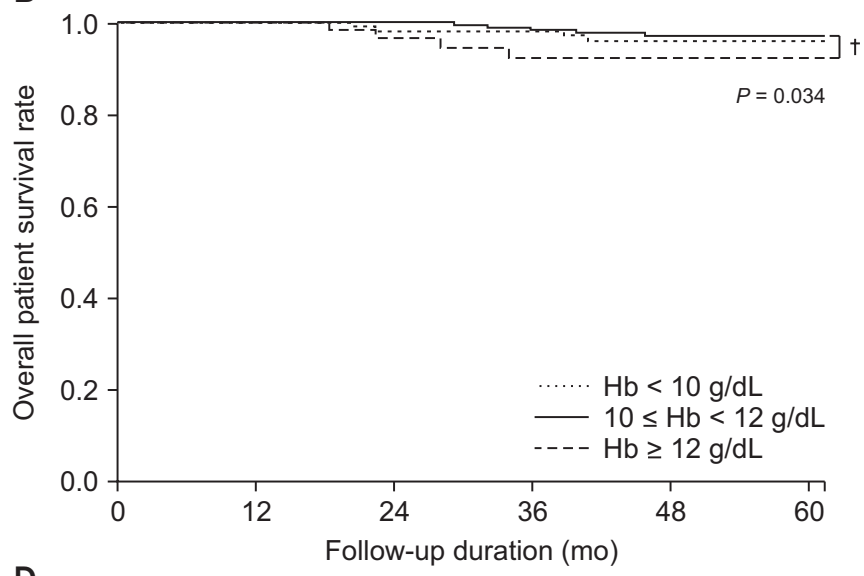

D

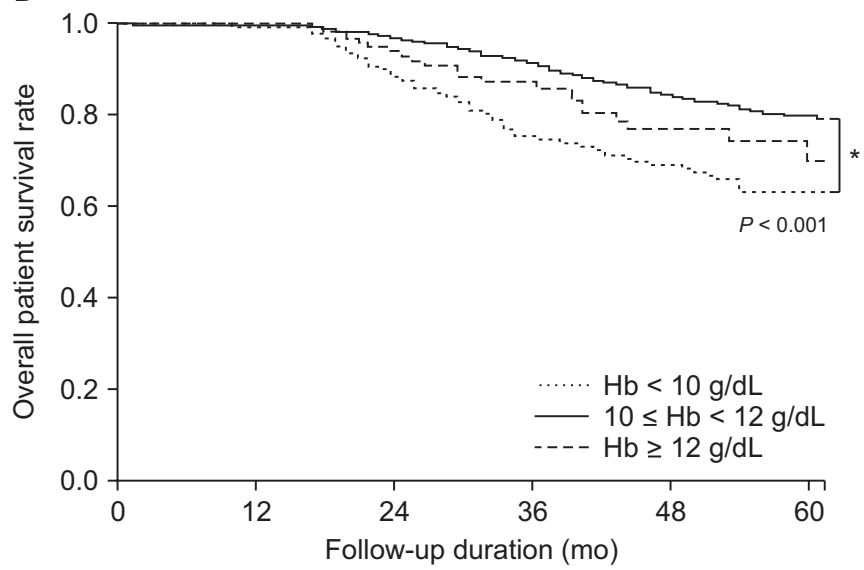

Figure 2. Comparison of patient survival according to patient age. (A) Survival according to hemoglobin (Hb) concentration in the overall population and in patients (B), under 40 years of age, $(C)$ between 40 to 60 years of age, and (D) over 60 years of age. $\star P<0.05$ vs. $\mathrm{Hb}<10,{ }^{\dagger} P<0.05$ vs. $10 \leq \mathrm{Hb}<12$. 
$( \pm 1.8)$ in the age $<40$ group, $29.3( \pm 1.1)$ months in the $40 \leq$ age $<60$ group, and $28.0( \pm 1.2)$ months in the age $\geq$ 60 months group. Mean serum albumin concentrations, which generally reflect the nutritional status of dialysis patients, did not differ among the three age groups $(P=$ 0.337). Other anemia profiles, such as mean serum ferritin and TSAT concentrations also did not differ between the groups ( $P=0.126, P=0.136$ for each $)$.

\section{Overall patient survival}

A total of 363 deaths were reported among the overall study population during the follow-up period (24.4 months; range, 3-81 months). In the overall patient population, the patient survival rate was greatest in the $10 \leq$ $\mathrm{Hb}<12 \mathrm{~g} / \mathrm{dL}$ group, but there was no difference between the $\mathrm{Hb} \geq 12 \mathrm{~g} / \mathrm{dL}$ and $\mathrm{Hb}<10 \mathrm{~g} / \mathrm{dL}$ groups $(P=0.459$; Fig. 2A). Within the $40 \leq$ age $<60$ years and age $\geq 60$ years groups, the $10 \leq \mathrm{Hb}<12 \mathrm{~g} / \mathrm{dL}$ group had significantly superior overall patient survival compared to the $\mathrm{Hb}<10 \mathrm{~g} /$ dL group $(P=0.006$ for the $40 \leq$ age $<60$ years; $P<0.001$ for the age $\geq 60$ years). There was a trend toward better overall patient survival in the $\mathrm{Hb} \geq 12 \mathrm{~g} / \mathrm{dL}$ group compared to the $\mathrm{Hb}<10 \mathrm{~g} / \mathrm{dL}$ group, but the difference was not statistically significant $(P=0.919$ for the $40 \leq$ age $<60$ years group; $P=0.086$ for the age $\geq 60$ years group; Fig. $2 \mathrm{C}, \mathrm{D})$. The $\mathrm{Hb} \geq 12 \mathrm{~g} / \mathrm{dL}$ group had inferior overall survival than the $10 \leq \mathrm{Hb}<12 \mathrm{~g} / \mathrm{dL}$ group $(P=0.034)$, whereas survival of the $\mathrm{Hb}<10 \mathrm{~g} / \mathrm{dL}$ group was comparable to that in the $10 \leq \mathrm{Hb}<12 \mathrm{~g} / \mathrm{dL}$ group $(P=0.475$; Fig. $2 \mathrm{~B})$.

In a Cox proportional hazards model, for both the $40 \leq$ age $<60$ years and age $\geq 60$ years groups, a lower $\mathrm{Hb}$ concentration $(\mathrm{Hb}<10 \mathrm{~g} / \mathrm{dL})$ was associated with significantly increased risk of all causes of death (adjusted HR, 1.719; 95\% CI, 1.158-2.252; $P=0.007$ in the $40 \leq$ age $<60$ years group; and adjusted HR, 2.098; 95\% CI, 1.567-2.808; $P<$ 0.001 in the age $\geq 60$ years group; Fig. $3 \mathrm{~B}, \mathrm{C}$ ), but no such association was found for the age $<40$ years group (Fig. $3 A)$.

\section{Cardiovascular disease (CVD)-related death}

A total of 105 cases of CVD-related death occurred during the follow-up period. Among the overall study population, the $10 \leq \mathrm{Hb}<12 \mathrm{~g} / \mathrm{dL}$ group had the lowest incidence of CVD-related death $(P<0.001)$. In the age

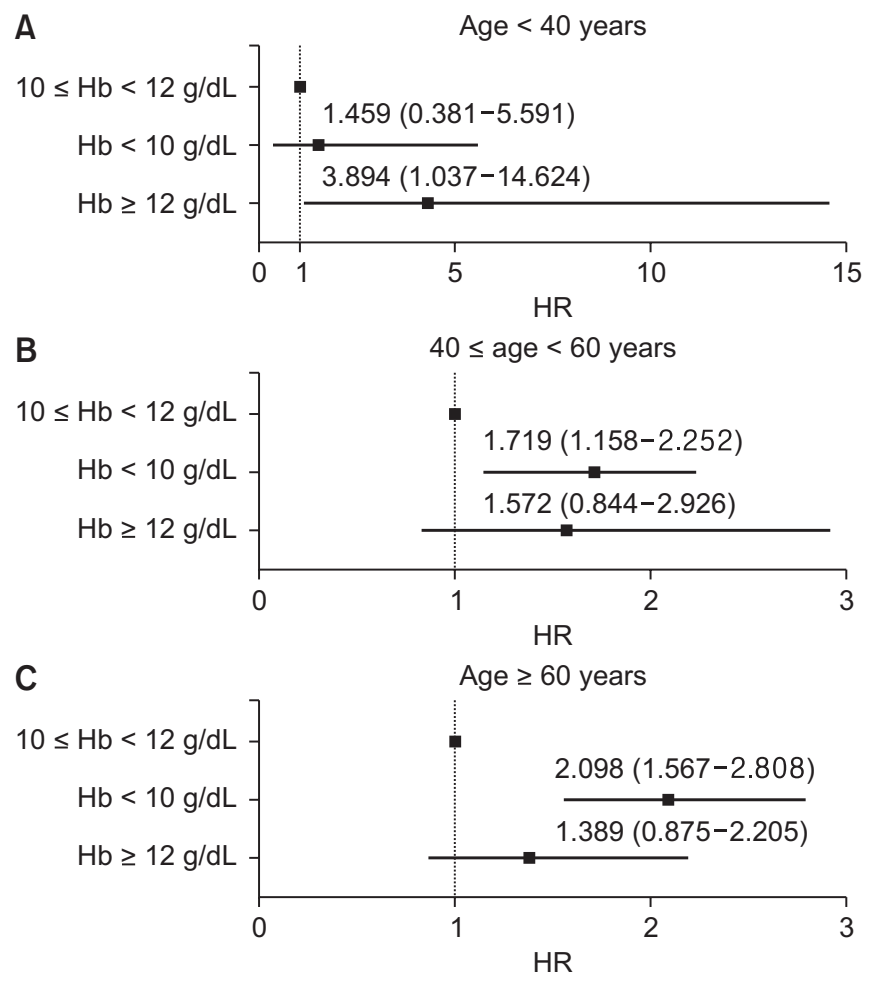

Figure 3. Forest plot of hazard ratios (HR) for overall mortality. All-cause mortality stratified by hemoglobin $(\mathrm{Hb})$ level for patients (A) under 40 years of age, (B) aged between 40 to 60 years, and (C) over 60 years of age.

$<40$ years and $40 \leq$ age $<60$ years groups, the incidence of CVD-related death was not different among the three $\mathrm{Hb}$ concentration groups (Fig. 4B, C). In contrast, in the age $\geq 60$ years group, the lower $\mathrm{Hb}$ group $(\mathrm{Hb}<10 \mathrm{~g} / \mathrm{dL})$ had the greatest incidence of CVD-related death among the three groups $(P<0.001$; Fig. 4D). In the multivariate analyses, after adjustment for sex, primary renal disease, and duration of dialysis, a lower $\mathrm{Hb}$ concentration $(\mathrm{Hb}<$ $10 \mathrm{~g} / \mathrm{dL}$ ) was an independent risk factor for CVD-related death in the age $\geq 60$ years group (adjusted HR, 2.796; 95\% CI, 1.669-4.686; $P<0.001$; Fig. 5C). The Hb concentration was not significant associated with the incidence of CVDrelated death in the age $<40$ years and $40 \leq$ age $<60$ years groups (Fig. 5A, B).

\section{Overall hospitalization and cardiovascular hospitalization}

A total of 2,188 (64.2\%) patients were hospitalized during the follow-up period. In the overall study population, the $\mathrm{Hb}<10 \mathrm{~g} / \mathrm{dL}$ group had a significantly greater incidence of hospitalization $(n=605,70.5 \%)$ than the $10 \leq \mathrm{Hb}<$ 
A

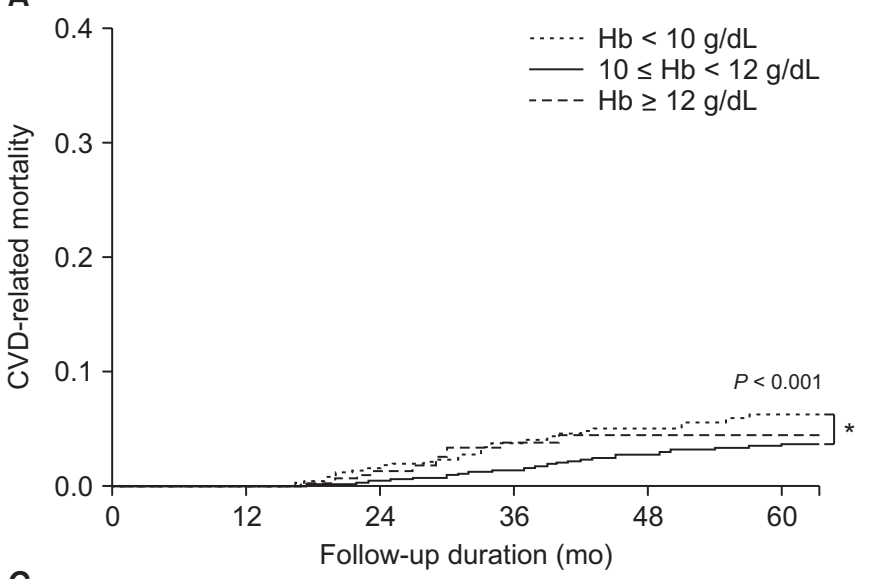

C

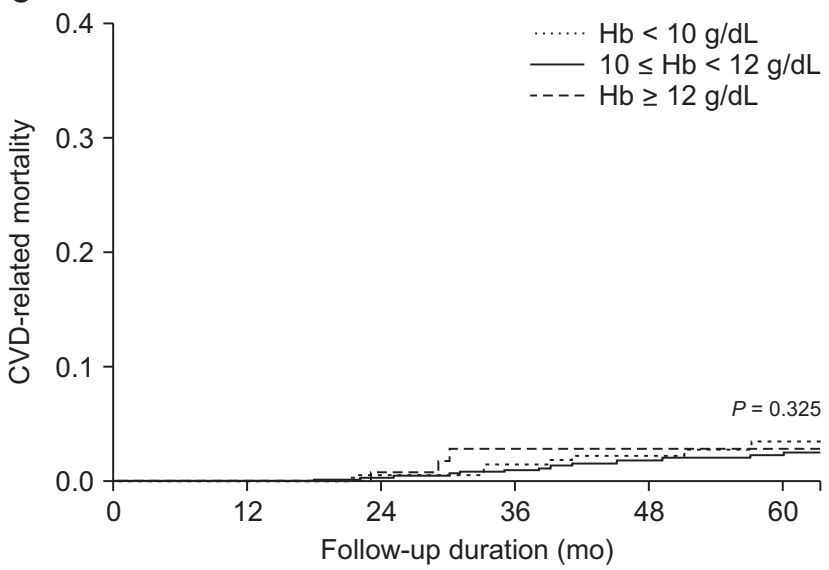

B

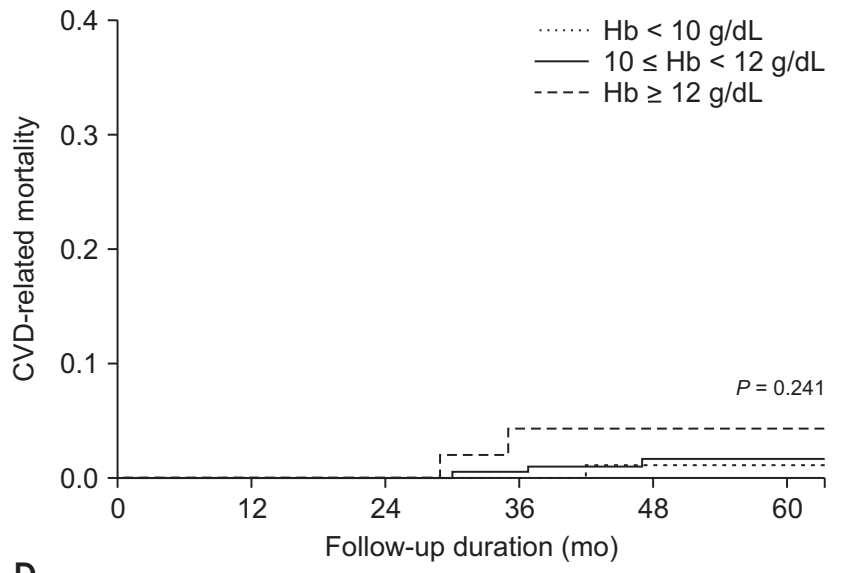

D

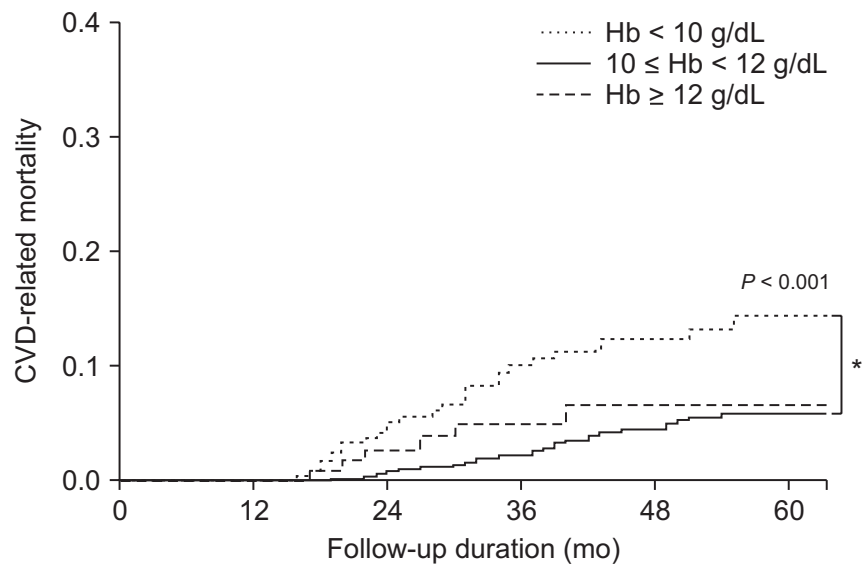

Figure 4. Comparison of cardiovascular disease (CVD)-related death according to patient age. (A) CVD-related death according to hemoglobin ( $\mathrm{Hb}$ ) concentration in the overall population, (B) in patients under 40 years of age, (C) aged between 40 to 60 years, and (D) over 60 years of age.

$\star P<0.05 \mathrm{vs} . \mathrm{Hb}<10$.

$12(\mathrm{n}=1,392,62.8 \%)$ and $\mathrm{Hb} \geq 12 \mathrm{~g} / \mathrm{dL}$ groups $(\mathrm{n}=191$, $57.0 \%$; $P$ values for all $<0.05)$. Fig. 6 shows the hazard ratios (HR) of all-cause and CVD-related hospitalization according to patient age and mean $\mathrm{Hb}$ concentration, after adjustment for sex, primary renal disease, and duration of dialysis. In the age $<40$ years group, there were no significant differences in overall hospitalization according to the mean $\mathrm{Hb}$ concentration. However, among the $40 \leq$ age $<60$ years and age $\geq 60$ years groups, $\mathrm{Hb}<10 \mathrm{~g}$ / $\mathrm{dL}$ itself increased the risk of overall hospitalization as compared to $10<\mathrm{Hb} \leq 12$ (adjusted HR, 1.572; 95\% CI, 1.213-2.036; $P=0.001$, for the $40 \leq$ age $<60$ years group; adjusted HR, 1.455; 95\% CI, 1.037-2.043; $P<0.001$, for the age $\geq 60$ years group). Among the age $<40$ years and $40 \leq$ age $<60$ years groups, a target $\mathrm{Hb} \geq 12 \mathrm{~g} / \mathrm{dL}$ did not significantly influence CVD-related hospitalization; whereas, among elderly patients (age $>60$ years), a target
$\mathrm{Hb} \geq 12 \mathrm{~g} / \mathrm{dL}$ significantly reduced the risk of all-cause hospitalization (adjusted HR, 0.544; 95\% CI, 0.362-0.820; $P=0.004$ ) and CVD-related hospitalization (adjusted HR, $0.463 ; 95 \%$ CI, $0.242-0.887 ; P=0.020$ ).

\section{Discussion}

In this study, we found that overcorrected Hb concentrations or anemia in dialysis patients had differential impacts on the clinical outcomes according to the patient's age. The impact of anemia was more significant in elderly ESRD patients than in the young patients. In contrast, overcorrected $\mathrm{Hb}$ concentrations had more significant impact in the younger ESRD patients. Therefore, our results suggest that a differential approach based on the patient's age is required for the management of anemia in dialysis patients. 


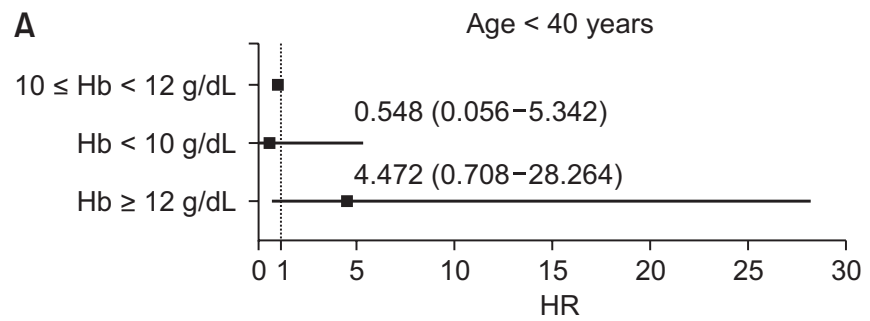

B
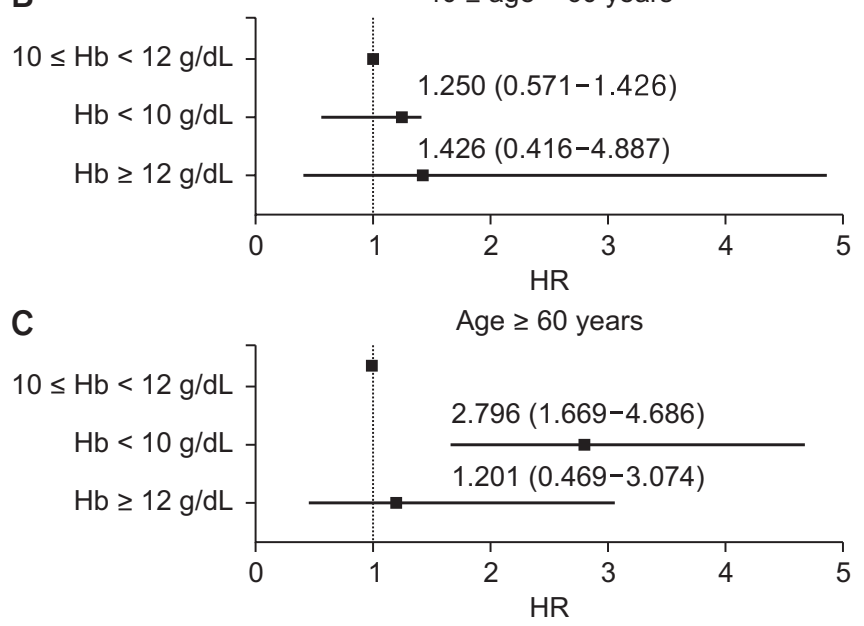

Figure 5. Forest plot of hazard ratios (HR) for cardiovascular disease (CVD)-related mortality. All-cause mortality stratified by hemoglobin $(\mathrm{Hb})$ level for patients $(\mathrm{A})$ under 40 years of age, $(B)$ between 40 to 60 years of age, and $(C)$ over 60 years of age.
We first compared the baseline characteristics according to the ages of the participants. We divided the patients into three age groups, age $<40,40 \leq$ age $<60$, and age $\geq 60$. The results of the baseline laboratory study indicated in all three age groups, most patients fell into the $10 \leq \mathrm{Hb}<12 \mathrm{~g} / \mathrm{dL}$ group ( $56 \%$ to $69 \%$ ), followed by the $\mathrm{Hb}<10 \mathrm{~g} / \mathrm{dL}$ and $\mathrm{Hb} \geq 12 \mathrm{~g} / \mathrm{dL}$ groups respectively. Compared to the other age groups, the overcorrection rate was slightly greater in the age $<40$ years group with $\mathrm{Hb} \geq 12$ $\mathrm{g} / \mathrm{dL}$, which reflects the tendency to set higher $\mathrm{Hb}$ targets for younger patients. However, the serum albumin concentration, which reflects the nutritional status of dialysis patients, did not differ among the three age groups, nor did serum ferritin or TSAT concentrations. Other markers related to anemia, such as iPTH, and C- reactive protein concentrations, also did not differ according to the patient's age. These findings suggest that the baseline condition associated with anemia may not differ according to the patient's age.

Next, we investigated the impact of anemia on overall patient survival in each age group. As we expected, patient survival was greatest when the patient's Hb concentration ranged between 10 and $12 \mathrm{~g} / \mathrm{dL}$, in both the overall patient population and each age subgroup. However, anemia $(\mathrm{Hb}<10 \mathrm{~g} / \mathrm{dL})$ had differential effects on overall
A

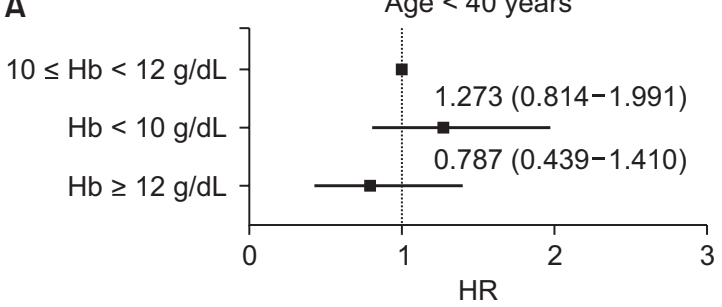

C

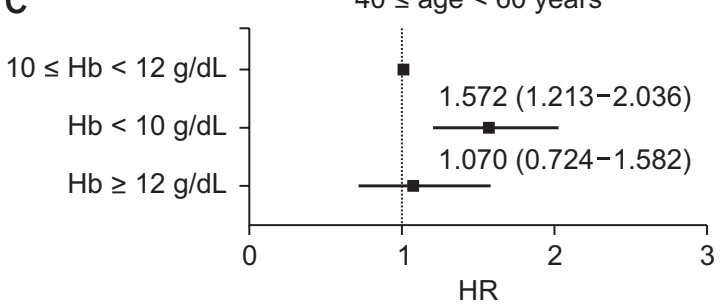

E

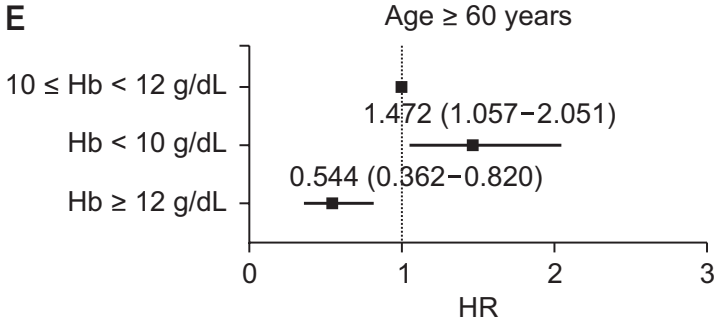

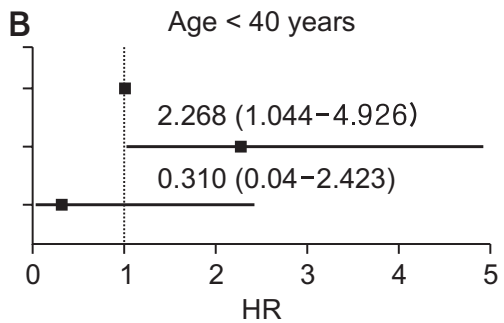

D
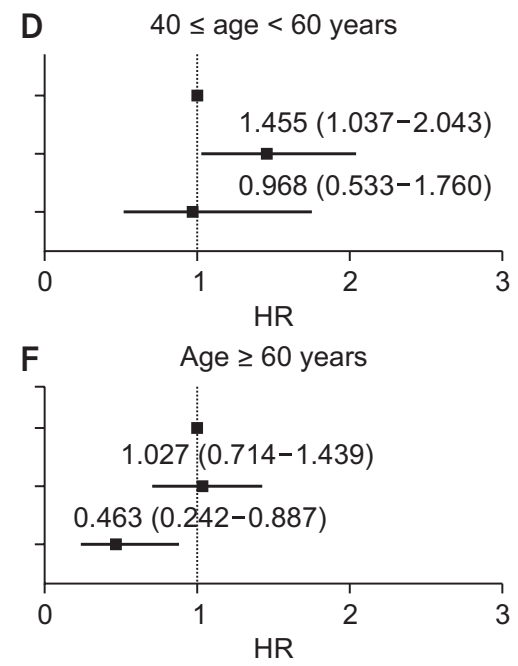

Figure 6. Forest plot of hazard ratios (HR) of (A) all-cause hospitalization and (B) cardiovascular disease (CVD)related hospitalization of patients under $\mathbf{4 0}$ years of age, (C) all-cause hospitalization and (D) CVD-related hospitalization of patients between 40 and 60 years of age, (E) all-cause hospitalization and (F) CVD-related hospitalization of patients over 60 years of age stratified by hemoglobin (Hb) concentration. 
patient survival according to the patient's age: anemia was associated with lower patient survival in elderly patients, but did not influence survival in the younger patient groups. When we compared the incidence of CVDrelated death between the young and elderly patients according to their $\mathrm{Hb}$ concentrations, the incidence of CVD-related mortality was greater when $\mathrm{Hb}<10 \mathrm{~g} / \mathrm{dL}$, which indicated that undercorrection of anemia in elderly patients is associated with greater risk of CVD-related deaths. These trends were also confirmed in a review of the multivariate analyses.

This differential impact may be partially accounted for by the association between frailty and anemia in elderly patients $[9,10]$. In elderly populations, mild anemia is independently associated with an increased risk of frailty, and the poorer prognosis associated with lower $\mathrm{Hb}$ concentrations may be related to decreased physical activity $[11,12]$. The risk of CVD-related death may be attributed to the tissue hypoxia caused by anemia, which promotes left ventricular hypertrophy (LVH), thereby causing death in elderly patients [13]. Previous studies have reported that aging increases the incidence and severity of $\mathrm{LVH}$ in dialysis patients. Furthermore, $\mathrm{Hb}$ was found to be an age-dependent risk factor for LVH [14]. The effect may be more pronounced in elderly patients, who are vulnerable to LVH [15]. Anemia promotes cardiac structural and functional abnormalities, and is a CVD-related death risk factor in ESRD, especially in elderly dialysis patients $[16,17]$. Thus, further considerations or investigations are required [18].

Indeed, many previous reports have suggested that the incidence of hospitalization in ESRD patients is associated with a significant decline in $\mathrm{Hb}$ [19], and aging and frailty synergistically increased the risk of all-cause and CVD-related hospitalization [20]. Interestingly, among elderly dialysis patients, higher $\mathrm{Hb}$ concentrations were associated with significantly reduced risk for all-cause and CVD-related hospitalization, a finding which was seen to be inconsistent with young dialysis patients. This result may suggest that maintaining $\mathrm{Hb}$ concentrations within a more physiologically normal range ( $\geq 12 \mathrm{~g} / \mathrm{dL}$ ) may be adequate for reducing the short-term risk of all-cause and cardiovascular morbidity in elderly HD patients; however, further investigation may be required to clarify this issue and its clinical applications.

Some studies have reported that the effect of anemia on overall or cardiovascular mortality may be less significant in young ESRD patients as compared to elderly ESRD patients, since they have fewer comorbid conditions [2123]. In addition, the prevalence of CVD among young adults with ESRD is lower than in elderly ESRD patients, and the types of CVD are also considered different. For example, the most common cardiovascular diagnoses in young ESRD patients have been reported to include $\mathrm{LVH}$, congestive heart failure, and arrhythmias, whereas coronary artery disease is most commonly found in elderly ESRD patients [24]. Thus, young ESRD patients do not appear to share the specific cardiovascular risk factors that are commonly present in elderly ESRD patients, and which may contribute to cardiovascular deaths associated with higher $\mathrm{Hb}$ concentrations. Therefore, young ESRD patients with may be better able to tolerate elevated $\mathrm{Hb}$ concentrations than elderly ESRD patients.

Accordingly, this present study must be understood in the context of the limitations of a large-scale registry analysis, and the possibility of unmeasured confounders. For example, the details of the patients' type of cardiovascular disease or of comorbidities were not available for analysis. Secondly, the follow-up duration of this registry was relatively short and the death and CVD-related death rarely occurred during this period. Third, this study defined old age as being greater than 60 years of age; however, the cut-off value defining 'old age' or 'elderly' status may be controversial and may differ from this assessment. Finally, the under 40 years of age group comprised a relatively small proportion of the overall study population, hence, the incidence of overall or CVD-related death may have been underestimated in this age group.

Taken together, anemia had a more significant impact on overall and CVD-related mortality and on the incidence of hospitalization in elderly patients on dialysis in comparison with the relatively young ESRD patients in our study. In contrast, elderly ESRD patients with a $\mathrm{Hb}$ concentration $\geq 12 \mathrm{~g} / \mathrm{dL}$ did not have an increased shortterm risk of all-cause mortality. Our results may suggest that more strict management of anemia in ESRD patients may be required in elderly ESRD patients, and also that there is a need for future prospective, randomized trials to identify an appropriate $\mathrm{Hb}$ target range to minimize the risk of CVD morbidity and mortality in elderly HD patients. 


\section{Conflicts of interest}

All authors have no conflicts of interest to declare.

\section{Funding}

This research was supported by a grant from the Korea Health Technology R\&D Project through the Korea Health Industry Development Institute (KHIDI), funded by the Ministry of Health \& Welfare, Republic of Korea (grant number: HC15C1129) and the Bio \& Medical Technology Development Program of the National Research Foundation (NRF) funded by the Ministry of Science \& ICT (2018M3A9E802151).

\section{Authors' contributions}

Eun Jeong Ko participated in designing this study and writing the paper. Yong Kyun Kim, Jang-Hee Cho, Yon Su Kim, Shin-Wook Kang, Nam-Ho Kim, and Yong-Lim Kim participated in collecting and analyzing the data. Chul Woo Yang participated in performing the study. Byung Ha Chung participated in designing the study.

\section{References}

[1] Pickett JL, Theberge DC, Brown WS, Schweitzer SU, Nissenson AR. Normalizing hematocrit in dialysis patients improves brain function. Am J Kidney Dis 1999;33:1122-1130.

[2] Roumelioti ME, Wentz A, Schneider MF, et al. Sleep and fatigue symptoms in children and adolescents with CKD: a cross-sectional analysis from the chronic kidney disease in children (CKiD) study. Am J Kidney Dis 2010;55:269-280.

[3] Gerson A, Hwang W, Fiorenza J, et al. Anemia and healthrelated quality of life in adolescents with chronic kidney disease. Am J Kidney Dis 2004;44:1017-1023.

[4] Locatelli F, Nissenson AR, Barrett BJ, et al. Clinical practice guidelines for anemia in chronic kidney disease: problems and solutions. A position statement from kidney disease: improving global outcomes (KDIGO). Kidney Int 2008;74:1237-1240.

[5] KDOQI. KDOQI clinical practice guideline and clinical practice recommendations for anemia in chronic kidney disease: 2007 update of hemoglobin target. Am J Kidney Dis 2007;50:471-530.

[6] Besarab A, Bolton WK, Browne JK, et al. The effects of nor- mal as compared with low hematocrit values in patients with cardiac disease who are receiving hemodialysis and epoetin. N Engl J Med 1998;339:584-590.

[7] Rheault MN, Molony JT, Nevins T, Herzog CA, Chavers BM. Hemoglobin of $12 \mathrm{~g} / \mathrm{dl}$ and above is not associated with increased cardiovascular morbidity in children on hemodialysis. Kidney Int 2017;91:177-182.

[8] Tanaka M, Komaba H, Fukagawa M. Emerging association between parathyroid hormone and anemia in hemodialysis patients. Ther Apher Dial 2018;22:242-245.

[9] Sy J, Johansen KL. The impact of frailty on outcomes in dialysis. Curr Opin Nephrol Hypertens 2017;26:537-542.

[10] Lee SY, Yang DH, Hwang E, et al. The prevalence, association, and clinical outcomes of frailty in maintenance dialysis patients. J Ren Nutr 2017;27:106-112.

[11] Röhrig G. Anemia in the frail, elderly patient. Clin Interv Aging 2016;11:319-326.

[12] Bianchi VE. Role of nutrition on anemia in elderly. Clin Nutr ESPEN 2016;11:e1-e11.

[13] Chang JM, Chen SC, Huang JC, Su HM, Chen HC. Anemia and left ventricular hypertrophy with renal function decline and cardiovascular events in chronic kidney disease. Am J Med Sci 2014;347:183-189.

[14] Tripepi G, Mattace-Raso F, Sijbrands E, et al. Aging and left ventricular mass and function in people with end-stage renal disease. J Am Geriatr Soc 2011;59:1636-1641.

[15] Antikainen RL, Peters R, Beckett NS, et al. Left ventricular hypertrophy is a predictor of cardiovascular events in elderly hypertensive patients: hypertension in the very elderly trial. J Hypertens 2016;34:2280-2286.

[16] Zoccali C, Benedetto FA, Mallamaci F, et al. Left ventricular mass monitoring in the follow-up of dialysis patients: prognostic value of left ventricular hypertrophy progression. Kidney Int 2004;65:1492-1498.

[17] Akaishi M, Hiroe M, Hada Y, Suzuki M, Tsubakihara Y, Akizawa T; KRN321 Study Group. Effect of anemia correction on left ventricular hypertrophy in patients with modestly high hemoglobin level and chronic kidney disease. $J$ Cardiol 2013;62:249-256.

[18] Villain C, Ecochard R, Bouchet JL, et al. Relative prognostic impact of nutrition, anaemia, bone metabolism and cardiovascular comorbidities in elderly haemodialysis patients. Nephrol Dial Transplant 2019;34:848-858.

[19] Ofsthun N, Labrecque J, Lacson E, Keen M, Lazarus JM. The effects of higher hemoglobin levels on mortality and hospitalization in hemodialysis patients. Kidney Int 
2003;63:1908-1914.

[20] Afilalo J, Alexander KP, Mack MJ, et al. Frailty assessment in the cardiovascular care of older adults. J Am Coll Cardiol 2014;63:747-762.

[21] Locatelli F, Aljama P, Canaud B, et al.; Anaemia Working Group of European Renal Best Practice (ERBP). Target haemoglobin to aim for with erythropoiesis-stimulating agents: a position statement by ERBP following publication of the trial to reduce cardiovascular events with Aranesp therapy (TREAT) study. Nephrol Dial Transplant 2010;25:2846-
2850.

[22] Mikhail A, Brown C, Williams JA, et al. Renal association clinical practice guideline on anaemia of chronic kidney disease. BMC Nephrol 2017;18:345.

[23] Prichard SS. Comorbidities and their impact on outcome in patients with end-stage renal disease. Kidney Int 2000;57 Suppl 74:S100-S104.

[24] Muirhead N. Individualizing anaemia treatment: a discussion of case histories. Nephrol Dial Transplant 2005;20 Suppl 6:vi37-vi43. 